\title{
Enoxaparin in Suspected Heparin Induced Thrombocytopenia: An Observational Follow-Up in Critically Ill Patients
}

\author{
Mohammad Taghi Beigmohammadi*1, Zahid Hussain Khan ${ }^{2}$ and HosseinKhalili ${ }^{3}$ \\ ${ }^{1}$ Department of Anesthesiology and Intensive Care, University of Medical Sciences, Iran \\ ${ }^{2}$ Department of Anesthesiology and Intensive Care, Tehran University of Medical Sciences, Iran \\ ${ }^{3}$ Department of Pharmacotherapy, Tehran University of Medical Sciences, Iran
}

Received: March 16, 2018; Published: April 05, 2018

*Corresponding author: Mohammad Taghi Beigmohammadi, Department of Anesthesiology and Intensive Care, Faculty of Medicine, Tehran University of Medical Sciences, Tehran, Iran, Tel: +98.2161192828; Fax: +98.2166581537; Email: mbage46@gmail.com

Abstract

Background: HIT is overdiagnosedin ICU patients and this leads to inappropriate use of direct agents and bleeding. In this observational study safety use of enoxaparine in critically ill patients with high probable HIT has been evaluated. Materials and Methods: In observational study, out of 564 patients admitted to the ICUs during 2012-2014, 88 patients with suspected HIT based on the clinical criteria (4Ts score) received either enoxaparin $(n=48)$ or no treatment as control group $(n=40)$. All of the patients had normal platelet count at hospital admission developed thrombocytopenia (plt $<100000 / \mu \mathrm{l}$ ).The patients were followed for 5 days for any evidence of thromboemboli, bleeding, petechiae, cutaneous necrosis. Doppler ultrasound of the lower limbs was performed as indicated and the peripheral blood smear was obtained for detection of platelet aggregation. A p value less than 0.05 was considered statistically significant.

Results: Return of platelet count to the normal range value occurred more frequently in the enoxaparin than the control group. Frequency of clinical HIT based on the 4Ts score was not significantly different between the groups. Thrombosis was less in enoxaparine than the control group ( $4.2 \%$ vs. $15 \%$ ) and in follow up Doppler ultrasound, new thrombosis was not seen in the enoxaparine group.

Conclusion: Clinical HIT 4Ts score is not a valid tool for evaluation of HIT in critically ill patients and thus HIT is usually over-diagnosed. A reliable clinical HIT scoring for critically ill patients is necessary.

Keywords: Heparin; Thrombocytopenia; Enoxaparin; Critically ill patients

Abbreviations: HIT: Heparin Induced Thrombocytopenia; TCP: Thrombo-Cyto-Penia; VTE: Vein Thrombo-Embolism; LMWH: Low Molecular Weight Heparin; UFH: Un-Fractionated Heparin; PBS: Peripheral Blood Smear; DTH: Drug Induced Thrombocytopenia

\section{Introduction}

Heparin induced thrombocytopenia (HIT) is one of the several causes of thrombocytopenia (TCP) in critically ill patients. HIT is a dose-independent and immune-mediated reaction. When heparin binds platelet factor 4, conformational change in the complex occurs and becomes immunogenic. In circulation, IgG is the most common generated heparin-PF4 antibodies [1]. HIT may be serious enough to cause significant morbidity and mortality [1]. Venous thrombus formation and bleeding have been reported in $22 \%-80 \%$ and $5 \%$ of patients following HIT, respectively [2,3]. In 10-15\% of cases, thrombosis may occur before reduction in the platelet count even after discontinuation of heparin [2,4]. Critically ill patients always need to vein thromboembolism (VTE) prophylaxis, pharmacological (such as, unfractionated heparin or low molecular weight heparin) or mechanical. After development of HIT, heparin and other heparinoids are contraindicated [1,5]. However improvement in TCP following low molecular weight heparin (LMWH) administration in patients with HIT has been reported in some observational studies and case reports [6-13]. Although HITis rare with an incidence of $0.3 \%$ to $0.5 \%$ in critically ill patients [14-16], but it is very frequently considered as a potential cause for TCP in ICU patients, then it is suspected more often than actually confirmed and over-diagnosed [4,14,16-18].

Recent studies have showed the use of clinical $4 \mathrm{~T}$ scoring in critically ill is not reliable and may be lead to inappropriate use of direct agents and then increase of bleeding rate [4,19-21]. HIT is occurred more common with unfractionated heparin (UFH) than 
with LMWH use (4.8\% vs. $0.6 \%$ ) [22,23]. Innumerable causes and complex mechanisms of TCP in ICU make it difficult to approach and diagnose the etiology with certainty. Owing to the relatively scant access and failure of the laboratory tests as the sole agents in establishing a net diagnosis of HIT and grave outcome of HIT, efforts have been made in using alternative agents of heparin. Although release serotonin assay were proposed as a standard laboratory test to confirm HIT, but considering the high cost and unavailability, it is not used routinely [19]. On the other hand, because of unavailability and not-defined antidotes, use of heparinalternative in patients with probable HIT is not practical in many centers [21]. Regardless, the clinical suspicion to HIT should be confirmed if results of laboratory tests are positive [23,24]. For these reasons, some patients with suspected HIT may be candidate to receive enoxaparin instead of heparin. In this observational study, clinical outcomes of patients with high probable HIT who received enoxaparin were monitored.

\section{Methods}

\section{Patient Population and Setting}

This prospective observational study was conducted between May 2012 and November 2014 in the general and surgical ICUs of Imam Khomeini Hospital Complex. The hospital is a tertiary, referral, teaching hospital affiliated to Tehran University of Medical Sciences, Tehran, Iran. The study protocol was approved by the Ethics Committee of Tehran University of Medical Sciences. Patients with normal platelet count at the time of ICU admission, receiving therapeutic heparin for at least 5 days, a platelet count $<100000 /$ $\mu \mathrm{l}$ following heparin treatment and a clinical 4 Ts score $>3$ were recruited. Patients with history of thrombocytopenia, chemotherapy in recent 3 months, use of large doses of corticosteroids, ant platelet agents and NSAIDs, dialysis or Plasmapheresis were excluded. Out of 564 patients admitted to the ICUs during the study period, 88 patients were confirmed as suspected HIT based on hematologist consultation. The patients were enrolled into two groups based on physician decision to receive either enoxaparin $(n=48)$ or no treatment as control group $(n=40)$. If a diagnosis of HIT was suspected based on the criteria of clinical HIT [25] and a 4Ts score above 3 , heparin was stopped and treatment with a direct thrombin inhibitor was initiated.

Because of expenses, no patients could provide direct agents. Routinely and based on risk - benefit and probability of HIT, some patients received enoxaparin 40-60 mg (Clexan, Sanofi Co., France) subcutaneously twice daily $(n=60)$ and other patients got no treatment and were just observed $(n=48)$. Clinical HIT criteria is a reduction of platelet count $>50 \%$ from the baseline at least 5 days after treatment with heparin, occurrence or exacerbation of thrombosis or cutaneous ecchymosed or necrosis and exclusion of other possible causes of thrombocytopenia [25]. Based on the 4Ts score, the patients were divided to moderate (score 4-5) and high (score 6-8) probability of HIT. The patients were followed for 5 days for any evidence of thromboembolism, bleeding (such as gastrointestinal bleeding), petechiae, cutaneous necrosis, and Doppler ultrasound of the lower limbs was performed as indicated.
A peripheral blood smear (PBS) was obtained for detection of platelet aggregation and schistosis. In addition, patient's sex, gender, acute physiology and chronic health evaluation II (APACHE II) score at the time of ICU admission, duration of stay in ICU and mechanical ventilation, and CBC were recorded. In the enoxaparin group, enoxaparin was withheld if the platelet count was less than $50000 / \mu \mathrm{l}$, or progression or appearance of a fresh thrombus was confirmed.

\section{Statistical Analysis}

The Kolmogorov-Smirnov test was used to assess the normal distribution of continuous variables. Data are presented as mean \pm standard deviation. The independent sample t-test and MannWhitney U test were used for statistical analysis of normally and non-normally distributed data respectively. Categorical variables were reported as percentages. Chi square or Fisher exact test (if more than $20 \%$ of the categories had expected frequencies less than 5, was used to evaluate possible associations among categorical variables. Statistical analyses were applied by the SPSS 16 application (SPSS Inc., Chicago). A p value less than 0.05 was considered statistically significant.

\section{Results}

There was no significant difference regarding the baseline demographic, laboratory and clinical characteristics of patients in the enoxaparin and control groups (Table 1).

Table 1: Baseline characteristics of the patients.

\begin{tabular}{|c|c|c|c|}
\hline$P$ value & No- Enoxaparin & Enoxaparin & Variable \\
\hline 0.196 & $\begin{array}{l}21(52.5 \%) \\
19(47.5 \%)\end{array}$ & $\begin{array}{l}32(66.7 \%) \\
16(33.3 \%)\end{array}$ & $\begin{array}{c}\text { Sex; n (\%) } \\
\text { Male } \\
\text { Female }\end{array}$ \\
\hline 0.017 & $43.4 \pm 13.7$ & $49.9 \pm 11.5$ & Age, mean $\pm S D$ (years) \\
\hline 0.449 & $221.8 \pm 26.2$ & $227.3 \pm 40.9$ & $\begin{array}{l}\text { Platelet (count } / \mu \mathrm{l}) \text {, } \\
\text { mean } \pm \mathrm{SD},(\text { day } 0)\end{array}$ \\
\hline 0.653 & $5.1 \pm 1.6$ & $5.2 \pm 1.5$ & $\begin{array}{c}\mathrm{RBC}(\text { count } / \mu \mathrm{l}), \\
\text { mean } \pm \mathrm{SD},(\text { day } 0)\end{array}$ \\
\hline 0.292 & $8.4 \pm 1.2$ & $9.4 \pm 1.9$ & $\begin{array}{l}\mathrm{WBC}(\text { count } / \mu \mathrm{l}) \text {, } \\
\text { mean } \pm \mathrm{SD},(\text { day } 0)\end{array}$ \\
\hline 0.917 & $17 \pm 4.9$ & $16.9 \pm 4.2$ & $\begin{array}{c}\text { APACHE II score, } \\
\text { mean } \pm \text { SD }\end{array}$ \\
\hline 0.205 & $5.9 \pm 2.9$ & $6.8 \pm 3.6$ & Days of MV, mean $\pm \mathrm{SD}$ \\
\hline 0.084 & $8.3 \pm 3.9$ & $10.2 \pm 5.3$ & $\begin{array}{l}\text { ICU stay, mean } \pm \text { SD } \\
\text { (day) }\end{array}$ \\
\hline 0.798 & $\begin{array}{c}12(30 \%) \\
7(17.5 \%) \\
12(30 \%) \\
8(20 \%) \\
1(2.5 \%)\end{array}$ & $\begin{array}{c}18(37.5 \%) \\
11(22.9 \%) \\
12(25 \%) \\
6(12.5 \%) \\
1(2.1 \%)\end{array}$ & $\begin{array}{c}\text { Type of disease } \\
\text { Sepsis } \\
\text { M.T } \\
\text { Surgery } \\
\text { Neurologic } \\
\text { Others }\end{array}$ \\
\hline
\end{tabular}

Plt: plate lets, RBC: red blood cells, WBC: white blood cells, APACHE: acute physiology and chronic health Evaluation, MV: mechanical ventilation, M.T: multi trauma. 
Return of platelet count to the normal range value occurred more frequently in the enoxaparin than the control group $(\mathrm{P}=0.002, \mathrm{OR}=$ $4.1,95 \% \mathrm{CI}=1.6-9.8)$. However the time needed for correction of thrombocytopenia was comparable between the groups $(\mathrm{P}=0.95)$. The peripheral blood smear findings including schistocytes, platelet aggregation and number of platelets were not significantly different between the groups. The minimum and maximum 4Ts scores in the patients were 4 and 7 respectively. Frequency of clinical HIT based on the 4Ts score was not significantly different between the groups $(\mathrm{P}=0.521$. $\mathrm{OR}=1.4,95 \% \mathrm{CI}=0.6-3.4)$. In Doppler ultrasound assessment, 6 and 2 patients experienced venous thrombus formation or progression in the control and enoxaparin groups respectively $(\mathrm{P}=0.134, \mathrm{OR}=0.3,95 \% \mathrm{CI}=0.04-1.29)$. Active bleeding was not observed in any of the cases. Clinical characteristics of the patients are being summarized (Table 2).

Table 2: Comparison of variables in two groups.

\begin{tabular}{|c|c|c|c|}
\hline$P$ value & $\begin{array}{c}\text { No- } \\
\text { enoxaparin }\end{array}$ & Enoxaparin & Variable \\
\hline 0.835 & $9.7 \pm 2.6$ & $9.5 \pm 2.5$ & $\begin{array}{c}\text { Time of TCP after start of } \\
\text { heparin (day) }\end{array}$ \\
\hline 0.002 & $\begin{array}{l}14(29.2 \%) \\
25(62.5 \%)\end{array}$ & $\begin{array}{l}34(70.8 \%) \\
15(37.5 \%)\end{array}$ & $\begin{array}{c}{ }^{*} \text { Correction of TCP } \\
\text { Yes } \\
\text { No }\end{array}$ \\
\hline 0.947 & $1.8 \pm 0.7$ & $1.7 \pm 0.8$ & Correction day of TCP \\
\hline 0.486 & $\begin{array}{c}18 \\
7 \\
12 \\
3\end{array}$ & $\begin{array}{c}29 \\
8 \\
9 \\
2\end{array}$ & $\begin{array}{c}\text { PBS at first day of study } \\
\text { (n) } \\
\text { Match with CBC } \\
\text { Shistocytosis } \\
\text { Aggregation } \\
\text { Shisto. \&Aggre. }\end{array}$ \\
\hline 0.232 & $\begin{array}{c}19 \\
7 \\
9 \\
5\end{array}$ & $\begin{array}{c}28 \\
6 \\
11 \\
3\end{array}$ & $\begin{array}{c}\text { PBS at fifth day of study } \\
\text { (n) } \\
\text { Match with CBC } \\
\text { Shistocytosis } \\
\text { Aggregation } \\
\text { Shisto. \&Aggre. }\end{array}$ \\
\hline 0.521 & $\begin{array}{l}22(50 \%) \\
11(50 \%)\end{array}$ & $\begin{array}{l}18(47.2 \%) \\
26(52.7 \%)\end{array}$ & $\begin{array}{c}\text { +HIT 4Ts score } \\
\text { Moderate } \\
\text { High }\end{array}$ \\
\hline 0.134 & $6(15 \%)$ & $2(4.2 \%)$ & $\begin{array}{l}\text { ++Thrombosis in } \\
\text { dopplerultrasound }\end{array}$ \\
\hline
\end{tabular}

TCP: thrombocytopenia, PBS: peripheral blood stream, CBC; count of blood cells,

${ }^{*} \mathrm{OR}=4.1,+\mathrm{OR}=1.4,++\mathrm{OR}=0.3$

\section{Discussion}

TCP is a valuable marker in predicting the severity of illnesses and may be used as a prognostic factor in critically ill patients. Also it is inversely related to the length of ICU stay and mortality $[4,14,21,26]$. Precise assessment of patients with TCP, considering differential diagnosis and probable causes are essential to carry out an effective treatment. Uncorrected decline in platelets counts during the first 4 days following surgery was strongly associated with the length of ICU stay and patients' mortality [21]. A fall in platelet count occurring during the first 5-7 days of hospitalization mostly reflects consumptive coagulopathy and bone marrow depression and thus could herald the severity of the disease and multiorgan failure [21]. In medical patients without bleeding, bacterial and fungal infections are the most common causes of TCP [21]. TCP is a common finding in critically ill patients. Approximately 8- $68 \%$ and 13-44\% of these patients had or experienced TCP at the time of ICU admission or ICU stays respectively [4,21,27].

Drug induced thrombocytopenia (DIT) is the most common cause of TCP in critically ill patients [28-29]. Although, heparin is the leading cause of DIT, but the incidence of HIT in critically ill patients is quite low (1\% of all cases) and rarely confirmed [3,20,28-30]. It has been shown that compared to heparin, LMWHs released less amount of PF4 upon contact with platelets $[1,5]$. Although use of LMWHs in established cases of HIT has not been recommended $[1,8]$, safety of these agents in such patients has been reported [6-7]. Although antibody production could be triggered by the use of LMWHs but due to antibody titer compared to UFH, type of antibody, molecular size of the anticoagulant, and low propensity of LMWHs for attachment to PF4, clinical HIT may not be worsened [1,4,25,31]. In Slocum's study [3], 126 patients with established diagnosis of clinical HIT were evaluated and it was found that plasma samples of 83 patients (65.9\%) in the presence of enoxaparin did not show platelet aggregation and in 2 patients who needed anticoagulant therapy enoxaparin was used successfully. They concluded that the use of enoxaparin was probably safe in patients in whom the platelets had not undergone aggregation in contact with enoxaparin.

When HIT is highly probable, heparinoids discontinuation and replacement with a direct thrombin inhibitor is recommended [28]. In situations of no access to laboratory facilities to confirm HIT and non-availability or cost consideration of alternative drugs, administration of enoxaparin under close surveillance may be only option. Although frequency of thrombosis episodes in this study was more common in the control than in the enoxaparin group (6 vs. 2) but this difference was statistically non-significant. Despite a high probability of HIT in enoxaparin group based on the median of 4Ts score, new thrombosis formation or progression of an old thrombosis was not detected in the patients' follow-up. It could be due to over diagnosis of HIT, and non-applicability of clinical HIT 4Ts scoring system in the diagnosis of HIT in critically ill patients. This point has been noted and probable corrections of 4Ts scoring scale have been proposed by Crowther et al. [20] and Fiorenza et al. [19].

Because of receiving concomitant multiple drugs and interventions, infections, systemic illnesses and the two non-specific signs of HIT (thrombocytopenia and thrombosis) diagnosis of HIT is really complex in critically ill patients [5,14,32]. Appropriate approaches should be made for investigating the etiology of TCP, managing acute illnesses, and considering an effective strategy regarding platelet administration [5]. 14C-serotonin release assay as a gold standard test is available only in limited centers, and in 
addition detection of antibody against platelets to document HIT is not recommended except in special conditions [4,28]. Although absence of antibody against PF4/heparin complex can exclude probability of HIT, but diagnosis of HIT based on the laboratory test solely may be overestimated as detecting positive heparin-PF4 antibody is more common than clinical HIT $[16,28]$. Also, clinical HIT diagnosis based on the 4Ts scale is not valid and has high false positives in ICU and could result in over diagnosing HIT in critically ill patients [4,19-20]. In the study of Crowther et al. [14], 33 out of $261(12.6 \%)$ patients with suspected HIT had negative standard serotonin test.

In our study, 26 patients $(52.6 \%)$ in the enoxaparine group were declared to have suspected HIT and although having received enoxaparin, TCP got corrected more frequently without increased thrombosis formation (Table 2). It is to be kept in mind that all alternative anticoagulants of heparin in the therapeutic doses obviously increased bleeding (0.8\% - $1.25 \%$ per treatment day). Also, no antidote has been identified yet for these agents and thus they are not routinely recommended [21]. There are two options for anticoagulation after heparin discontinuation: lepirudin (a direct thrombin inhibitor) and Danaparoid (a heparanoid). Lepirudin demonstrates no cross- reactivity with heparin-induced antibodies and requires measuring aPTTs for monitoring anticoagulation [5]. In contrast Danaparoid cross-reacts weakly with heparin-induced antibodies in 10 to $40 \%$ of HIT sera and requires measuring antifactor Xa levels for anticoagulation monitoring [5].

For these reasons, in some centers alternative anticoagulants are used in the prophylactic doses instead of the therapeutic doses till the final laboratory diagnosis of HIT is established [21]. In addition to cost, non-availability and safety issues led to limited use of heparin alternatives in our country. Therefore, the optimal management planning for suspected HIT in critically ill patients depends on actual probability of HIT [4]. If the patient does not have thrombosis, follow-up for any evidence of thrombosis through Doppler ultrasound is recommended [4]. In this study, thrombosis was less in enoxaparine than the control group (4.2\% vs. 15\%) and in follow up Doppler ultrasound new thrombosis was not been seen in enoxaparine group. Our study was conducted on critically ill patients with a wide variety of medical and surgical problems that could affect the results of the study. Further interventional studies to define appropriate criteria for diagnosis of HIT in critically ill patients are recommended.

\section{Conclusion}

In critically ill patients, TCP due to several etiologies is a common finding. To confirm clinical HIT 4Ts score is not a valid tool for evaluation of HIT in critically ill patients and thus it is usually over-diagnosed. Considering availability, safety and cost of heparinalternatives, precise laboratory tests and a reliable clinical HIT scoring for critically ill patients is mandatory.

\section{References}

1. Walenga JM, Jeske WP, Prechel MM, Bacher P, Bakhos M (2004) Decreased Prevalence of Heparin-Induced Thrombocytopenia with Low-Molecular-
Weight Heparin and Related Drugs. Semin Thromb Hemost 30(supp 1): 69-80.

2. Warkentin TE (1999) Heparin-induced thrombocytopenia: a ten-year retrospective. Annu Rev Med 50: 129-147.

3. Slocum MM, Adams JG, Teel R, Spadone DP, Silver D (1996) Use of enoxaparin in patient with heparin-induced thrombocytopenia syndrome. J Vasc Surg 23(5): 839-843.

4. Priziola JL, Smythe MA, Dager WE (2010) Drug-induced thrombocytopenia in critically ill patients. Crit Care Med 38(S6): 145154 .

5. Drews RE, Weinberger SE (2000) Thrombocytopenic disorders in critically ill patients. Am J Respir Crit Care Med 162(2): 347-351.

6. Leroy J, Leclerc MH, Delahousse B, Guérois C, Foloppe P, et al. (1985) Treatment of heparin- associated thrombocytopenia and thrombosis with low molecular weight heparin (CY 216). Semin Thromb Hemost 11(3): 326-329.

7. Robitaille D, Leclerc JR, Laberge R, Sahab P, Atkinson S, et al. (1992) Cardiopulmonary bypass with a low-molecular-weight heparin fraction (enoxaparin) in a patient with a history of heparin-associated thrombocytopenia. J Thorac Cardiovasc Surg 103(3): 597-599.

8. Roussi JH, Houbouyan LL, Goguel AF (1984) Use of low molecularweight heparin in heparin-induced thrombocytopenia with thrombotic complications. Lancet 1: 1183.

9. Chong B, Magnani H (1992) Orgaran in heparin-induced thrombocytopenia. Hemostasis 22(2): 85-91.

10. Chong B, Ismail F, Cade J, Gallus A, Gordon S, et al. (1989) Heparininduced thrombocytopenia: studies with a new low molecular weight heparinoid, Org 10172. Blood 73(6): 1592-1596.

11. Greinacher A, Michel I, Kiefel V, Mueller-Ekhardt C (1991) A rapid and sensitive test for diagnosing heparin- associated thrombocytopenia. Tromp Haemost 66(6): 734-736.

12. Ortel T, Gockerman J, Califf R, McCann RL, O'Connor CM, et al. (1992) Parenteral anticoagulation with the heparinoidiomoparan (Org 10172) in patients with heparin induced thrombocytopenia and thrombosis. ThrombHae most 67: 292-296.

13. Rowlings P, Mansberg R, Rozenberg M (1991) The use of a low molecular weight heparinoid (Org 10172) for extracorporeal procedures in patients with heparin dependent thrombocytopenia and thrombosis. Aust NZ J Med 21(1): 52-54.

14. Crowther MA, Cook DJ, Meade MO (2005) Thrombocytopenia in medicalsurgical critically ill patients: prevalence, incidence, and risk factors. J Crit Care 20(4): 348-353.

15. Crowther MA, Cook DJ, Albert M, Williamson D, Meade M, et al. (2010) the 4Ts scoring system for heparin-induced thrombocytopenia in medicalsurgical intensive care unit patients. J Crit Care 25(2): 287-293.

16. Selleng K, Warkentin TE, Greinacher A (2007) Heparin-induced thrombocytopenia in intensive care patients. Crit Care Med 35(4): 11651176.

17. Verma AK, Levine M, Shalansky SJ, Carter CJ, Kelton JG (2003) Frequency of heparin-induced thrombocytopenia in critical care patients. Pharmacotherapy 23(6): 745-753.

18. Gettings EM, Brush KA, Van Cott EM, William E Hurford (2006) Outcome of postoperative critically ill patients with heparin-induced thrombocytopenia: An observational retrospective casecontrolstudy. Crit Care 10(6): 1-7.

19. Fiorenza MA, Frazee EN, Personett HA, Dierkhising RA, Schramm GE (2014) Assessment of a modified 4T scoring system for heparin-induced thrombocytopenia in critically ill patients. J Crit Care 29(3): 426-431. 
20. Crowther M, Cook D, Guyatt G, Zytaruk N, McDonald E, et al. (2014) Heparin-induced thrombocytopenia in the critically ill: Interpreting the 4Ts test in a randomized trial. J Crit Care 29(3): 477-492.

21. Greinacher A, Selleng K (2010) Thrombocytopenia in the Intensive Care Unit Patient. Hematology pp. 135-143.

22. Warkentin TE, Roberts RS, Hirsh J, Kelton JG (2003) An Improved Definition of Immune Heparin-Induced Thrombocytopenia in Postoperative Orthopedic Patients. Arch Intern Med 163(20): 25182524.

23. Martel N, Lee J, Wells PS (2005) Risk for heparin-induced thrombocytopenia with unfractionated and low-molecular-weight heparin thromboprophylaxis: a meta-analysis. Blood 106(8): 27102715 .

24. Greinacher A, Amiral J, Dummel V, Vissac A, Kiefel V, et al. (1994) Laboratory diagnosis of heparin-associated thrombocytopenia and comparison of platelet aggregation test, heparininduce plateletactivation test, and platelet factor4/ heparin enzyme-linked immunosorbent assay. Transfusion 34(5): 381-385.

25. Lo GK, Juhl D, Warkentin TE, Igouin CSS, Eichler P, et al. (2006) Evaluation of pretest clinical score (4 T's) for the diagnosis of heparin-induced thrombocytopenia in two clinical settings. J Throm Haemost 4(4): 759765.

26. Vandijck DM, Blot SI, De Waele JJ, Hoste EA, Vandewoude KH, et al. (2010) Thrombocytopenia and outcome in critically ill patients with bloodstream infection. Heart Lung 39(1): 21-26.

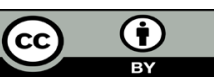

This work is licensed under Creative Commons Attribution 4.0 License

Submission Link: https://biomedres.us/submit-manuscript.php
27. Hui P, Cook DJ, Lim W, Fraser GA, Arnold DM (2011) The frequency and clinical significance of thrombocytopenia complicating critical illness: a systematic review. Chest 139(2): 271-278.

28. Stasi R (2012) How to approach thrombocytopenia? Hematology 2012(1): 191-197.

29. Drews RE (2003) Critical issues in hematology: anemia, thrombocytopenia, coagulopathy, and blood product transfusions in critically ill patients. Clin Chest Med 24(4): 607-622.

30. Crespo EM, Oliveira GBF, Honeycutt EF (2009) Evaluation and management of thrombocytopenia and suspected heparin induced thrombocytopenia in hospitalized patients: The complications after thrombocytopenia caused by heparin (CATCH) registry. Am Heart J 157(4): 651-657.

31. Walenga JM, Koza MJ, Lewis BE, Pifarre R (1996) Relative heparininduced thrombocytopenic potential of low molecular weight heparins and new antithrombotic agents. Clin Appl ThrombHemost 2: 21-27.

32. Selleng S, Malowsky B, Strobel U (2010) Early-onset and persisting thrombocytopenia in post-cardiac surgery patients is rarely due to heparin-induced thrombocytopenia, even when antibody tests are positive. J Thromb Haemost 8(1): 30-36.

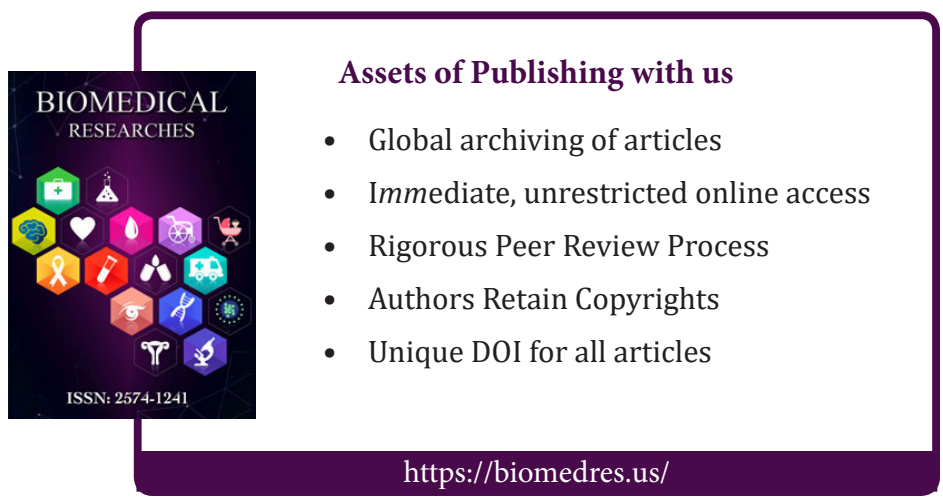

